\title{
Stem Cells for Neurovascular Repair in Stroke
}

\section{Kazutaka Shinozuka, Travis Dailey, Naoki Tajiri, Hiroto Ishikawa, Dae Won Kim, Mibel Pabon, Sandra Acosta, Yuji Kaneko, and Cesar V Borlongan*}

Department of Neurosurgery and Brain Repair, University of South Florida College of Medicine, 12901 Bruce B. Downs Blvd. MDC78, Tampa, Florida 33612, USA

\begin{abstract}
Stem cells exert therapeutic effects against ischemic stroke via transplantation of exogenous stem cells or stimulation of endogenous stem cells within the neurogenic niches of subventricular zone and subgranular zone, or recruited from the bone marrow through peripheral circulation. In this paper, we review the different sources of stem cells that have been tested in animal models of stroke. In addition, we discuss specific mechanisms of action, in particular neurovascular repair by endothelial progenitor cells, as key translational research for advancing the clinical applications of stem cells for ischemic stroke.
\end{abstract}

Keywords: Cerebral ischemia; Cell-based therapies; Vasculature; Blood brain barrier; Endothelial cells

\section{Stroke: A Significant Unmet Clinical Need}

Stroke is the third leading cause of death and the leading cause of long-term disability in the United States [1]. In 2004, the direct and indirect costs of stroke in the United States were estimated to be $\$ 53.6$ billion [2]. The mean lifetime cost of ischemic stroke to a single patient in the United States is estimated at $\$ 140,048$; this includes inpatient care, rehabilitation, and follow-up care necessary for lasting deficits. Approximately 2 out of every 1000 adults will have their first stroke in any given year in the United States [3]. The numbers of affected individuals, the costs necessary to facilitate their care, and rehabilitation coupled with the lack of therapies indicate that stroke represents a current significant unmet medical need.

The current therapy for stroke is limited [4-7]. Other than one recombinant protein therapy directed at the dissolution of thrombi in affected blood vessels in adults following stroke, tumor plasminogen activator or tPA, no specific treatment is available for either focal cerebral ischemia or global ischemic event. A major limitation with tPA is its very narrow therapeutic window of 4.5 hours after stroke onset. Beyond this timing of administration, tPA presents with deleterious side effects, in particular bleeding and hemorrhagic transformation, which can exacerbate stroke injury and counteract the benefits provided by reperfusion of the occluded artery [8]. To circumvent this limited tPA time to treat patients, telemedicine has been set-up in rural areas lacking access to medical centers $[9,10]$ in order to advance diagnosis of ischemic stroke and access to tPA within the limited therapeutic period. Unfortunately, such tele-stroke medicine remains in infancy with significant health disparity between rural and urban stroke care contributing to small population of stroke patients benefitting from tPA $[11,12]$. Investigations to small molecule therapies such as antiplatelet drugs, anticoagulants and statins acting as prophylactics have not produced consistent benefit following an acute attack, whereas neuroprotective compounds such as albumin and minocycline are recently being explored in clinical trials $[13,14]$. Because tPA is already an FDA-approved drug, finding strategies designed to extend its therapeutic window seems a highly logical lab-to-clinic translational route for introducing a novel therapy for stroke. Hence, a potent research strategy that dovetails on tPA's safety and efficacy profile, but also recognizes the drug's limitation and adverse effects, may reveal new avenues of treatment for stroke. To this end, we advance the approach that cell therapy can abrogate the blood brain barrier (BBB) breakdown associated with tPA especially when given beyond the 4.5 hours, and such BBB repair should extend tPA's therapeutic window, as well as directly benefit stroke in view of the BBB damage inherent in the disease itself.

This paper discusses the preclinical basis for testing stem cell therapy in stroke. We outline below the potential of cell-based therapy in circumventing the current limitations and deleterious side effects of tPA for treating stroke. Finally, we address the gap in knowledge concerning mechanisms underlying the therapeutic benefit of stem cells in stroke. Here, we highlight the underexplored concept of neurovascular repair as a major mode of action of cell therapy, and emphasize the major role of endothelial progenitor cells (EPC) as an effective cell source for transplantation. Our strategy is to exploit this neurovascular repair mechanism via EPC transplantation as a standalone or as an adjunct therapy for augmenting tPA treatment for stroke.

\section{Stem Cell-based Therapy for Stroke}

Several sources of stem cells have been demonstrated as safe and effective in animal models of stroke. Recently we reviewed various kinds of stem cell sources in detail [15]. In a historical order, the major types of cells transplanted in stroke include fetal-derived cells, neuroteratocarcinoma cells (NT2N), xenogenic pig-derived cells, embryonic stem (ES) cells, adult stem cells (bone marrow, human umbilical cord, placenta, amnion fluid, menstrual blood), and induced pluripotent stem cells (iPS). Due to ethical and logistical concerns, the use of adult stem cells has flourished over the last decade, which was further aided by a moratorium for using federal funds on ES research. Interestingly, the ongoing FDA-approved stem cell clinical trials in stroke use adult stem cells. For this section, we highlight the potential of adult bone marrow-derived endothelial progenitor cells in neurovascular repair for stroke.

Cell transplantation therapies and stem cell treatments have

*Corresponding author: Dr. Cesar V. Borlongan, University of South Florida College of Medicine, Department of Neurosurgery and Brain Repair, Tampa, USA, Tel: 813-974-3154; Fax: 813-974-3078; E-mail: cborlong@health.usf.edu

Received April 12, 2013; Accepted April 29, 2013; Published May 01, 2013

Citation: Shinozuka K, Dailey T, Tajiri N, Ishikawa H, Kim DW, et al. (2013) Stem Cells for Neurovascular Repair in Stroke. J Stem Cell Res Ther S4: 004. doi:10.4172/2157-7633.S4-004

Copyright: (c) 2013 Shinozuka K, et al. This is an open-access article distributed under the terms of the Creative Commons Attribution License, which permits unrestricted use, distribution, and reproduction in any medium, provided the original author and source are credited. 
emerged as potential treatments for numerous diseases and medical conditions, including stroke. One approach using stem cells involved the direct transplantation of neural stem cells (NSCs) into the damaged region of the brain. NSCs transplanted following transient global ischemia differentiated into neurons and improved spatial recognition in rats [16]. Post-mitotic neuron-like cells (NT2N) cells, derived from a human embryonal carcinoma cell line, migrated over long distances after implantation into brains of immuno-competent newborn mice and differentiated into neuron- and oligodendrocyte-like cells [17]. NT2N cells promoted functional recovery following focal cerebral ischemia after direct transplantation [18]. Similarly, MHP36 cells, a stem cell line derived from mouse neuroepithelium, improved functional outcome in rats after global ischemia [19] and also following focal cerebral ischemia or stroke [20]. NCSs grafted into brain developed morphological and electrophysiological characteristics of neurons [21].

Other direct transplantation experiments in the brain have utilized cells derived from bone marrow. Bone marrow stromal cells (MSCs), when injected into the lateral ventricle of the brain, migrated and differentiated into astrocytes [22]. Fresh bone marrow transplanted directly into the ischemic boundary zone of rat brain improved functional recovery from middle cerebral artery occlusion [23]. Similarly, MSCs implanted into the striatum of mice after stroke, improved functional recovery [24]. MSCs differentiated into presumptive neurons in culture [25] and assumed functional neuronal characteristics in embryonic rats [26]. Intracerebral grafts of mouse bone marrow also facilitated restoration of cerebral blood flow and BBB after stroke in rats [27]. Indirect transplant methods, via intravenous or intra-arterial injection, also have been shown to afford positive effects. Following bone marrow transplantation with tagged donor cells, tagged bone marrow stem cells were shown to differentiate into microglia and astrocytic-like cells [28]. Intracarotid administration of MSCs following middle cerebral artery occlusion in a rat model improved functional outcome [29]. Similarly, intravenous administration of umbilical cord blood cells ameliorated functional deficits after stroke in rats [30]. Rats, which had received tagged bone marrow cell transplantation, showed the tagged cells as putative neurons and endothelial cells following middle cerebral artery occlusion and reperfusion [31]. It has also been reported that intravenous administration of cord blood cells was more effective than intra-striatal administration in producing functional benefit following stroke in rats [32]. Intravenous administration of MSCs has also been found to induce angiogenesis in the ischemic boundary zone following stroke in rats [33].

\section{Cell Replacement and By-stander Effects of Stem Cell Grafts}

It is unclear what brings about the purported benefit from stem cell transplantation. One possibility is the transformation of the transplanted cells into neurons [34]. There appears to be a positive relationship between the degree of behavioral improvement and the number of transplanted cells that stain positive for neuron specific markers [16]. However, transplanted cells often do not develop normal processes, and thus the benefit may not be mediated only by neuronal circuitry [35].

A second hypothesis that is not mutually exclusive is that the transplanted cells may also assist via differentiation into neuroectodermal derived cell types other than neurons. Marrow stromal cells migrate and transform into astrocytes [22]. Hematopoietic cells can differentiate into microglia and macroglia [28]. Bone marrow derived stem cells may also assist in blood vessel regeneration following brain tissue damage in several ways. The stromal cell derived factor-1 (SDF-1)/CXCR4 system assists in integration of cells into injured tissue by promoting the adhesion of CXCR4-positive cells onto vascular endothelium [36]. SDF-1 also augments vasculogenesis and neo-vasculogenesis of ischemic tissue by recruitment of endothelial progenitor cells [37]. Bone marrow is a source of these endothelial progenitors [38]. Adult bone marrow-derived cells have been shown to participate in angiogenesis by the formation of periendothelial vascular cells [39]. Intravenous administration of MSCs induced angiogenesis in the ischemic boundary zone after stroke [33]. We also observed that crude bone marrow is a source of endothelial cells after experimental stroke [31].

Trophic factors produced by the transplanted cells could be a factor. Via this mechanism, bone marrow grafts may assist in restoring brain blood flow and also repairing the BBB [27]. Trophic factors from marrow stromal cells may play a role in brain repair itself. Recent evidence suggests that intravenous administration of MSCs increases the expression of nerve growth factor and brain-derived neurotrophic factor following traumatic brain injury [40]. Understanding the exact mechanism(s) responsible for the therapeutic benefit seen following stem cell transplantation in the CNS is now at a critical junction in view of the planned FDA allowance for limited clinical trials of bone marrow-derived multipotent adult progenitor cells in acute ischemic stroke [41].

In accordance with the STAIR (Stroke Therapy Academic Industry Roundtable) and STEPS (Stem cell Therapeutics as an Emerging Paradigm for Stroke) criteria, investigations of the mechanism of action mediating experimental therapeutics in stroke are vital for extending their potential clinical utility $[42,43]$.

\section{An Underexplored Stroke Therapeutic Target: BBB repair}

A closely associated cell death cascade involved in stroke pathogenesis is impairment of the BBB, which further exacerbates brain damage. The central nervous system (CNS) is an immunologically privileged zone, protected from entry of immune cells and serum proteins by the BBB (as well as by the blood-spinal cord barrier and blood-cerebrospinal fluid barrier, but we will focus here on BBB). These CNS barriers control cerebral/spinal cord homeostasis by selective transport of molecules and cells [38-40,44,45]. This control is possible due to the unique structure of the microvasculature - in particular capillaries formed by endothelial cells which are connected via adherens and tight junctions [46-48]. Functional integrity of all $\mathrm{BBB}$ elements is critical for protection of the CNS from harmful blood substances. Impairment of this cellular machinery may cause BBB breakdown, leading to edema in many cases of brain diseases or injuries, including stroke. Degradation of the extracellular matrix may be concomitant with BBB disruption and tissue softening, leading to more pronounced brain swelling and to severe cerebral edema in stroke patients [49] and other brain disorders such as Alzheimer's disease [50] and multiple sclerosis [51,52]. Examination of BBB status in stroke reveals evidence of the barrier's altered permeability. Whereas the first phase of stroke is characterized by a surge in tissue $\mathrm{Na}+$ and water content concomitant with an increased pinocytosis and $\mathrm{Na}+$, $\mathrm{K}+$ ATPase activity across the endothelium, the second stage of stroke ensues with BBB breakdown that is associated with infarction of both the parenchyma and the vasculature itself [53]. At this second stage, tissue $\mathrm{Na}+$ level still remains, but the extravasation of serum proteases 
stands as a likely exacerbating factor [54]. Accumulating evidence implicates serum proteases in degradation of the extracellular matrix metalloproteinases (MMPs), which in turn aggravate BBB disruption and softening of the tissue, eventually manifesting into a well-defined form of brain swelling [53-55]. Part of the reason for the tPA's limited time window is that the surge in production of free radicals associated with delayed reperfusion brings a second wave of oxidative and nitrative stress that increases the risk of brain hemorrhage and edema [56]. With delayed reperfusion, there is a surge in production of superoxide, $\mathrm{NO}$, and peroxynitrate. Formation of these radicals in the vicinity of blood vessels plays an important role in reperfusion-induced injury. These radicals activate MMPs, which degrade collagen and laminin in the basal lamina, disrupting the integrity of the basement membrane and increasing $\mathrm{BBB}$ permeability. Oxidative and nitrative stress also triggers recruitment and migration of neutrophils and other leukocytes to the cerebral vasculature, which release enzymes that further increase basal lamina degradation and vascular permeability. These BBB pathological events can lead to parenchymal hemorrhage, vasogenic brain edema, and neutrophil infiltration into the brain [57]. In the clinic, significant brain edema, such as that seen in malignant MCA infarction, develops in a delayed fashion after large hemispheric strokes and accounts for a high mortality rate $(80 \%$ in the case of malignant MCA infarction) [58]. The primary BBB function is controlling CNS homeostasis by selective transport. Substances with molecular weights higher than 400 Da generally cannot cross the BBB by free diffusion. Some molecules cross the barriers via endothelial carrier-mediated or receptor-mediated transporters, see review $[38,39,44,59]$. It is possible that barrier disruption or dysfunction occurs in stroke, altering CNS homeostasis and allowing entry of harmful molecules from the periphery to the brain [60-62]. Among these injurious molecules are immune/ inflammatory factors, such as monocyte/macrophage cells, activated microglia, and reactive astrocytes possibly secreting proinflammatory cytokines, which have been detected in stroke patients and animal models [63-65]. Although additional studies are warranted to confirm the BBB status in stroke patients, the above results taken together imply that $\mathrm{BBB}$ dysfunction may contribute to stroke pathology. Thus, there could be an impaired endothelium-mediated mechanism in stroke leading to barrier dysfunction.

\section{EPC Therapy for BBB Repair in Stroke}

Endothelial progenitor cells (EPCs), initially described by Asahara et al. [66] are immature endothelial cells that circulate in peripheral blood. In their pioneering study, transplanted EPCs, isolated from human blood, were found in the endothelium of newly formed vessels in ischemic regions, indicating that a discrete cell population within the human blood participates in the formation of new vessels after ischemia. Griese et al. [67] also found that grafted EPCs populated the endothelium in animals with experimentally induced endothelial damage, further advancing the notion that EPCs contribute to the repair of damaged endothelium. The dogma that existed until recently is that neovascularization, or formation of new blood vessels, results exclusively from proliferation and migration of pre-existing endothelial cells, a process referred as to angiogenesis [68]. Furthermore, vasculogenesis or vascularization, defined as in situ differentiation of vascular endothelial cells from endothelial precursor cells, was thought to occur only in the embryo during vascular development. However, recent evidence has now established that circulating bone marrow-derived EPCs are capable of homing to neovascularization sites, proliferating, and differentiating into endothelial cells $[69,70]$. EPCs have been identified mainly in the mononuclear cell fraction of peripheral blood, leukapheresis products, and in umbilical cord blood [66,71], but can also be harvested from bone marrow. Over the last few years, EPCs have been studied as biomarkers to assess the risk of cardiovascular disease in human subjects. For example, a low EPC count predicts severe functional impairments in several cardiovascular pathologies such as diabetes [72], hypertension [73,74], scleroderma [75,76], aging [74,77], cigarettes smoking [74,78,79], and coronary artery disease [46]. In addition, EPCs have been examined as potent donor graft cells for transplantation therapy.

Transplantation of EPCs into ischemic tissues has emerged as a promising approach in the treatment of diseases with blood vessels disorders [80-82]. In mouse models of ischemic injury, EPCs injection led to improved neovascularization in hind limb ischemia [80-82]. Based largely on these laboratory findings suggesting angiogenic and vasculogenic potential of EPCs, clinical studies have been initiated to reveal whether patients with lower EPC numbers are at higher risk for atherosclerotic events, and whether patients with ischemic events may benefit from EPC administration [83].

Clinical studies to date suggest the therapeutic potential of EPC transplantation, although this assumption should be approached with much caution due to being open label trials, observational and/ or anecdotal accounts, and limited number of patients. Ex vivo expanded EPCs, isolated from peripheral blood mononuclear cells, can incorporate into the foci of myocardial neovascularization $[84,85]$, and intracoronary infusion of peripheral blood or bone marrow-derived progenitors in patients with acute myocardial infarction was associated with significant benefits in post-infarction remodeling [86-93]. Still in observational studies in patients with myocardial infarction, higher numbers of EPC correlate with better prognosis, more myocardial salvage [94], viability and perfusion [95], and more collaterals in the ischemic zone [96]. Randomized clinical trials on autologous bone marrow-derived cells are mixed; whereas transplanted coronary artery disease patients display improved left ventricular function at least in the short term [97], transplanted patients with chronic ischemic heart failure exhibit modest to no effects on change in left ventricular function [98].

Similar randomized trials of autologous bone marrow-derived cells have been carried out in patients with peripheral artery disease and showed improved endothelium-dependent vasodilation [99], ankle brachial index, rest pain, and pain-free walking time [100], but the degree of functional recovery was not as robust as seen in animal models. Clearly, these results are obtained from autologous bone marrow-derived cells, which are heterogenous with scarce number of EPCs, thus may not closely approximate EPC endpoints. For clinical application of EPCs in neurovascular disease, the available studies are much more limited with only 3 observational studies in patients with stroke. In 25 patients with an ischemic stroke, CD34+ cells peaked 7 days after stroke but generally reverted to baseline after 30 days [101]. Interestingly, higher CD34+ cell levels at 30 days related to higher numbers of infarcts on magnetic resonance imaging and also to cerebrovascular function as measured with positron emission tomography scanning (cerebral metabolic rate of oxygen, and cerebral blood flow). On the other hand, decreased numbers of clusters of rapidly adhering cells were seen after stroke and in "stable cerebrovascular disease," compared to controls free of vascular disease [102]. Higher age and the presence of cerebrovascular disease in general independently related to lower EPC numbers. The discrepancies in the results of these studies may be due to mismatched controls for age of patients and/ or the lack of methodological design for testing specific hypotheses on the causal role of EPC in cerebrovascular disease [102]. Although the primary mitigating mechanisms underlying stroke pathogenesis and 
its abrogation by cell therapy are still uncertain, there is substantial evidence implicating immunological attack upon the brain and/or its vasculature; widespread inflammatory reactions in stroke may trigger a cascade of events which alter the integrity of the $\mathrm{BBB}$, resulting in migration of leukocytes into the CNS. Leukocyte transmigration across the BBB during stroke immune/inflammatory processes could influence inter-endothelial junctional complex function leading to vascular endothelium damage and BBB breakdown. Equally a key component to our mechanism-based thesis is that disruption or dysfunction of the $\mathrm{BBB}$, preceding entry of harmful substances into the brain parenchyma, could be a key initial factor in stroke pathogenesis. Thus, restoration of barrier integrity may have a critical role in preventing stroke progression. Our studies have begun to address these questions, particularly, whether endothelial cell replacement can restore structural and functional properties of the BBB after stroke. Results of this study will provide the basis for pursuing cell therapy both for non-tPA and tPA-treated ischemic stroke patients, as well as for patients with neurodegenerative disorders characterized by BBB dysfunction.

\section{Conclusion}

The recognition that t-PA may exacerbate the breakdown of the already vulnerable $\mathrm{BBB}$ warrants therapies designed to arrest this $\mathrm{BBB}$ dysfunction. Currently, much of the stroke therapy implemented does not consider the capacity of BBB damage after stroke. It is our contention that if EPC transplantation promotes restoration of the vascular endothelium, the clinical effects could be far reaching and substantially help a large population of patients that may be excluded from the current therapeutic window guideline for tPA. Although a plethora of accumulating stem cell research is quickly translating into clinical trials, it is important to gain insights into the mechanisms of action, which will aid in optimizing the safety and efficacy of these stem cells in stroke. There are almost 800,00 stroke cases yearly in the USA but less than 3 percent of these patients benefit from tPA treatment, due to the drug's narrow therapeutic window and its detrimental side effects that can exacerbate stroke injury and counteract the benefits provided by reperfusion of the occluded artery. Accumulating evidence indicates that tPA-induced neurotoxicity may contribute to $\mathrm{BBB}$ breakdown and neuronal injury in the acute phase after stroke. BBB damage may result in the formation of severe brain edema over subsequent hours and days in stroke patients. This damage could negatively influence the CNS regenerative processes after stroke. Accordingly, any treatment regimen directed at attenuating stroke deficits should consider the pivotal role of $\mathrm{BBB}$ repair in order to maintain CNS homeostasis and enhance neuronal regeneration. In summary, structurally and functionally restoring the $\mathrm{BBB}$ in an acute and sub-acute stroke setting may afford therapeutic benefits against stroke. A regenerative mechanism involving the repair of the damaged BBB by EPC is critical to the successful outcome of cell therapy in stroke. Cell therapy tailored at EPC recruitment and/or directed secretion of EPC-soluble factors into the stroke brain stands as a potent strategy for BBB repair in stroke.

\section{Acknowledgement}

CVB is supported by NIH NINDS 5U01NS055914-04 and NIH NINDS R01NS071956-01, James and Esther King Foundation for Biomedical Research Program 1KG01-33966, and receives research grant support for his projects on bone marrow stem cell therapy for stroke from SanBio Inc., Celgene Cellular Therapeutics, KMPHC, and NeuralStem Inc.

\section{References}

1. Davenport R, Dennis M (2000) Neurological emergencies: acute stroke. J Neurol Neurosurg Psychiatry 68: 277-288.

\section{2. http://www.ncbi.nlm.nih.gov/pubmed/18237578}

3. Sudlow CL, Warlow CP (1996) Comparing stroke incidence worldwide: what makes studies comparable? Stroke 27: 550-558.

4. Fagan SC, Morgenstern LB, Petitta A, Ward RE, Tilley BC, et al. (1998) Costeffectiveness of tissue plasminogen activator for acute ischemic stroke. NINDS rt-PA Stroke Study Group. Neurology 50: 883-890.

5. Hess DC, Wang S, Hamilton W, Lee S, Pardue C, et al. (2005) REACH: clinical feasibility of a rural telestroke network. Stroke 36: 2018-2020.

6. Wang S, Gross H, Lee SB, Pardue C, Waller J, et al. (2004) Remote evaluation of acute ischemic stroke in rural community hospitals in Georgia. Stroke 35: 1763-1768.

7. Borlongan CV, Fournier C, Stahl CE, Yu G, Xu L, et al. (2006) Gene therapy, cell transplantation and stroke. Front Biosci 11: 1090-1101.

8. Wang X, Rosell A, Lo EH (2008) Targeting extracellular matrix proteolysis for hemorrhagic complications of tPA stroke therapy. CNS Neurol Disord Drug Targets 7: 235-242.

9. Switzer JA, Hall C, Gross H, Waller J, Nichols FT, et al. (2009) A web-based telestroke system facilitates rapid treatment of acute ischemic stroke patients in rural emergency departments. J Emerg Med 36: 12-18.

10. Leira EC, Hess DC, Torner JC, Adams HP Jr (2008) Rural-urban differences in acute stroke management practices: a modifiable disparity. Arch Neurol 65 887-891.

11. Henninger N, Chowdhury N, Fisher M, Moonis M (2009) Use of telemedicine to increase thrombolysis and advance care in acute ischemic stroke. Cerebrovasc Dis 27 Suppl 4: 9-14.

12. Wu O, Langhorne $P$ (2006) The challenge of acute-stroke management: does telemedicine offer a solution? Int J Stroke 1: 201-207.

13. Matsukawa N, Yasuhara T, Hara K, Xu L, Maki M, et al. (2009) Therapeutic targets and limits of minocycline neuroprotection in experimental ischemic stroke. BMC Neurosci 10: 126.

14. Hill MD, Moy CS, Palesch YY, Martin R, Dillon CR, et al. (2007) The albumin in acute stroke trial (ALIAS); design and methodology. Int J Stroke 2: 214-219.

15. Shinozuka K, Dailey T, Tajiri N, Ishikawa H, Kaneko Y, et al. (2013) Stem cel transplantation for neuroprotection in stroke. Brain Sci 3: 239-261.

16. Toda H, Takahashi J, Iwakami N, Kimura T, Hoki S, et al. (2001) Grafting neura stem cells improved the impaired spatial recognition in ischemic rats. Neurosc Lett 316: 9-12.

17. Ferrari A, Ehler E, Nitsch RM, Götz J (2000) Immature human NT2 cells grafted into mouse brain differentiate into neuronal and glial cell types. FEBS Lett 486 121-125.

18. Borlongan CV, Tajima Y, Trojanowski JQ, Lee VMY, Sanberg PR (1998) Transplantation of cryopreserved human embryonal carcinoma-derived neurons (NT2N cells) promotes functional recovery in ischemic rats. Exp Neurol 149: 310-321.

19. Veizovic T, Beech JS, Stroemer RP, Watson WP, Hodges H (2001) Resolution of stroke deficits following contralateral grafts of conditionally immorta neuroepithelial stem cells. Stroke 32: 1012-1019.

20. Modo M, Stroemer RP, Tang E, Veizovic T, Sowniski P, et al. (2000) Neurological sequelae and long-term behavioural assessment of rats with transient middle cerebral artery occlusion. J Neurosci Methods 104: 99-109.

21. Englund U, Bjorklund A, Wictorin K, Lindvall O, Kokaia M (2002) Grafted neural stem cells develop into functional pyramidal neurons and integrate into host cortical circuitry. Proc Natl Acad Sci U S A 99: 17089-17094.

22. Kopen GC, Prockop DJ, Phinney DG (1999) Marrow stromal cells migrate throughout forebrain and cerebellum, and they differentiate into astrocytes after injection into neonatal mouse brains. Proc Natl Acad Sci U S A 96: 1071110716.

23. Chen J, Li Y, Chopp M (2000) Intracerebral transplantation of bone marrow with BDNF after MCAo in rat. Neuropharmacology 39: 711-716.

24. Li Y, Chopp M, Chen J, Wang L, Gautam SC, et al. (2000) Intrastriata transplantation of bone marrow nonhematopoietic cells improves functional recovery after stroke in adult mice. J Cereb Blood Flow Metab 20: 1311-1319.

25. Woodbury D, Schwarz EJ, Prockop DJ, Black IB (2000) Adult rat and human 
bone marrow stromal cells differentiate into neurons. J Neurosci Res 61: 364370

26. Muñoz-Elias G, Marcus AJ, Coyne TM, Woodbury D, Black IB (2004) Adult bone marrow stromal cells in the embryonic brain: engraftment, migration, differentiation, and long-term survival. J Neurosci 24: 4585-4595.

27. Borlongan CV, Hadman M, Sanberg CD, Sanberg PR (2004) Central nervous system entry of peripherally injected umbilical cord blood cells is not required for neuroprotection in stroke. Stroke 35: 2385-2389.

28. Eglitis MA, Mezey E (1997) Hematopoietic cells differentiate into both microglia and macroglia in the brains of adult mice. Proc Natl Acad Sci U S A 94: 40804085 .

29. Li Y, Chen J, Wang L, Lu M, Chopp M (2001) Treatment of stroke in rat with intracarotid administration of marrow stromal cells. Neurology 56: 1666-1672.

30. Chen J, Sanberg PR, Li Y, Wang L, Lu M, et al. (2001) Intravenous administration of human umbilical cord blood reduces behavioral deficits after stroke in rats. Stroke 32: 2682-2688.

31. Hess DC, Hill WD, Martin-Studdard A, Carroll J, Brailer J, et al. (2002) Bone marrow as a source of endothelial cells and $\mathrm{NeuN}$-expressing cells After stroke. Stroke 33: 1362-1368.

32. Willing AE, Lixian J, Milliken M, Poulos S, Zigova T, et al. (2003) Intravenous versus intrastriatal cord blood administration in a rodent model of stroke. $J$ Neurosci Res 73: 296-307.

33. Chen J, Zhang ZG, Li Y, Wang L, Xu YX, et al. (2003) Intravenous administration of human bone marrow stromal cells induces angiogenesis in the ischemic boundary zone after stroke in rats. Circ Res 92: 692-699.

34. Riess $P$, Zhang C, Saatman KE, Laurer HL, Longhi LG, et al. (2002) Transplanted neural stem cells survive, differentiate, and improve neurological motor function after experimental traumatic brain injury. Neurosurgery 51 : 1043-1054.

35. Zhao LR, Duan WM, Reyes M, Keene CD, Verfaillie CM, et al. (2002) Human bone marrow stem cells exhibit neural phenotypes and ameliorate neurologica deficits after grafting into the ischemic brain of rats. Exp Neurol 174: 11-20

36. Peled A, Kollet O, Ponomaryov T, Petit I, Franitza S, et al. (2000) The chemokine SDF-1 activates the integrins LFA-1, VLA-4, and VLA-5 on immature human CD34(+) cells: role in transendothelial/stromal migration and engraftment of NOD/SCID mice. Blood 95: 3289-3296.

37. Yamaguchi J, Kusano KF, Masuo O, Kawamoto A, Silver M, et al. (2003) Stromal cell-derived factor-1 effects on ex vivo expanded endothelial progenitor cell recruitment for ischemic neovascularization. Circulation 107: 1322-1328.

38. Reyes M, Dudek A, Jahagirdar B, Koodie L, Marker PH, et al. (2002) Origin of endothelial progenitors in human postnatal bone marrow. J Clin Invest 109: 337-346.

39. Rajantie I, IImonen M, Alminaite A, Ozerdem U, Alitalo K, et al. (2004) Adult bone marrow-derived cells recruited during angiogenesis comprise precursors for periendothelial vascular mural cells. Blood 104: 2084-2086.

40. Mahmood A, Lu D, Chopp M (2004) Intravenous administration of marrow stromal cells (MSCs) increases the expression of growth factors in rat brain after traumatic brain injury. J Neurotrauma 21: 33-39.

41. Suárez-Monteagudo $C$, Hernández-Ramírez $P$, Alvarez-González L, GarcíaMaeso I, de la Cuétara-Bernal K, et al. (2009) Autologous bone marrow stem cell neurotransplantation in stroke patients. An open study. Restor Neurol Neurosci 27: 151-161.

42. Borlongan CV (2009) Cell therapy for stroke: remaining issues to address before embarking on clinical trials. Stroke 40: S146-148.

43. Feuerstein GZ, Zaleska MM, Krams M, Wang X, Day M, et al. (2008) Missing steps in the STAIR case: a Translational Medicine perspective on the development of NXY-059 for treatment of acute ischemic stroke. J Cereb Blood Flow Metab 28: 217-219.

44. Keene CD, Ortiz-Gonzalez XR, Jiang YH, Largaespada DA, Verfaillie CM et al. (2003) Neural differentiation and incorporation of bone marrow-derived multipotent adult progenitor cells after single cell transplantation into blastocyst stage mouse embryos. Cell Transplant 12: 201-213.

45. Di Nicola M, Carlo-Stella C, Magni M, Milanesi M, Longoni PD, et al. (2002) Human bone marrow stromal cells suppress T-lymphocyte proliferation induced by cellular or nonspecific mitogenic stimuli. Blood 99: 3838-3843.
46. Jorgensen C, Djouad F, Apparailly F, Noël D (2003) Engineering mesenchymal stem cells for immunotherapy. Gene Ther 10: 928-931.

47. Le Blanc K, Tammik L, Sundberg B, Haynesworth SE, Ringdén O (2003) Mesenchymal stem cells inhibit and stimulate mixed lymphocyte cultures and mitogenic responses independently of the major histocompatibility complex. Scand J Immunol 57: 11-20.

48. McIntosh K, Bartholomew A (2000) Stromal cell modulation of the immune system: A potential role for mesenchymal stem cells. Graft 3: 324-328.

49. Aggarwal S, Pittenger MF (2005) Human mesenchymal stem cells modulate allogeneic immune cell responses. Blood 105: 1815-1822.

50. Tse WT, Pendleton JD, Beyer WM, Egalka MC, Guinan EC (2003) Suppression of allogeneic T-cell proliferation by human marrow stromal cells: implications in transplantation. Transplantation 75: 389-397.

51. Le Blanc K, Rasmusson I, Sundberg B, Götherström C, Hassan M, et al. (2004) Treatment of severe acute graft-versus-host disease with third party haploidentical mesenchymal stem cells. Lancet 363: 1439-1441.

52. Reyes M, Verfaillie CM (2001) Characterization of multipotent adult progenito cells, a subpopulation of mesenchymal stem cells. Ann N Y Acad Sci 938 231-233.

53. Ayata C, Ropper AH (2002) Ischaemic brain oedema. J Clin Neurosci 9: 113 124

54. Busch E, Kruger K, Fritze K, Allegrini PR, Hoehn-Berlage M, et al. (1997) Bloodbrain barrier disturbances after rt-PA treatment of thromboembolic stroke in the rat. Acta Neurochirurgica Supplements 70: 206-208.

55. Kaur J, Zhao ZG, Klein GM, Lo EH, Buchan AM (2004) The neurotoxicity of tissue plasminogen activator? J Cereb Blood Flow Metab 24: 945-963.

56. Brouns R, De Deyn PP (2009) The complexity of neurobiological processes in acute ischemic stroke. Clin Neurol Neurosurg 111: 483-495.

57. Aoki T, Sumii T, Mori T, Wang XY, Lo EH (2002) Blood-brain barrier disruption and matrix metalloproteinase-9 expression during, reperfusion injury: Mechanical versus embolic focal ischemia in spontaneously hypertensive rats Stroke 33: 2711-2717.

58. Subramaniam S, Hill MD (2009) Decompressive hemicraniectomy for malignan middle cerebral artery infarction: an update. Neurologist 15: 178-184.

59. Chang CF, Lin SZ, Chiang YH, Morales M, Chou J, et al. (2003) Intravenous administration of bone morphogenetic protein-7 after ischemia improves moto function in stroke rats. Stroke 34: 558-564.

60. Castillo J, Alvarez-Sabín J, Martínez-Vila E, Montaner J, Sobrino T, et al (2009) Inflammation markers and prediction of post-stroke vascular disease recurrence: the MITICO study. J Neurol 256: 217-224.

61. Vila N, Castillo J, Dávalos A, Chamorro A (2000) Proinflammatory cytokines and early neurological worsening in ischemic stroke. Stroke 31: 2325-2329.

62. Castillo J, Leira R (2001) Predictors of deteriorating cerebral infarct: role of inflammatory mechanisms. Would its early treatment be useful? Cerebrovasc Dis 11 Suppl 1: 40-48.

63. Doyle KP, Simon RP, Stenzel-Poore MP (2008) Mechanisms of ischemic brain damage. Neuropharmacology 55: 310-318.

64. Wang GJ, Deng HY, Maier CM, Sun GH, Yenari MA (2002) Mild hypothermia reduces ICAM-1 expression, neutrophil infiltration and microglia/monocyte accumulation following experimental stroke. Neuroscience 114: 1081-1090.

65. Tang Y, Xu H, Du X, Lit L, Walker W, et al. (2006) Gene expression in blood changes rapidly in neutrophils and monocytes after ischemic stroke in humans: a microarray study. J Cereb Blood Flow Metab 26: 1089-1102.

66. Asahara T, Murohara T, Sullivan A, Silver M, vanderZee R, et al. (1997) Isolation of putative progenitor endothelial cells for angiogenesis. Science 275 964-967.

67. Griese DP, Ehsan A, Melo LG, Kong DL, Zhang LN, et al. (2003) Isolation and transplantation of autologous circulating endothelial cells into denuded vessels and prosthetic grafts: Implications for cell-based vascular therapy. Circulation 108: $2710-2715$

68. Carmeliet $P$ (2005) Angiogenesis in life, disease and medicine. Nature 438 932-936.

69. Masuda H, Asahara T (2003) Post-natal endothelial progenitor cells for 
neovascularization in tissue regeneration. Cardiovasc Res 58: 390-398.

70. Shi Q, Rafii S, Wu MH, Wijelath ES, Yu C, et al. (1998) Evidence for circulating bone marrow-derived endothelial cells. Blood 92: 362-367.

71. Bompais H, Chagraoui J, Canron X, Crisan M, Liu XH, et al. (2004) Human endothelial cells derived from circulating progenitors display specific functional properties compared with mature vessel wall endothelial cells. Blood 103 : 2577-2584.

72. Fadini GP (2008) An underlying principle for the study of circulating progenitor cells in diabetes and its complications. Diabetologia 51: 1091-1094.

73. Pirro M, Schillaci G, Menecali C, Bagaglia F, Paltriccia R, et al. (2007) Reduced number of circulating endothelial progenitors and HOXA9 expression in CD34+ cells of hypertensive patients. J Hypertens 25: 2093-2099.

74. Umemura T, Soga J, Hidaka T, Takemoto H, Nakamura S, et al. (2008) Aging and hypertension are independent risk factors for reduced number of circulating endothelial progenitor cells. Am J Hypertens 21: 1203-1209.

75. Del Papa N, Quirici N, Soligo D, Scavullo C, Cortiana M, et al. (2006) Bone marrow endothelial progenitors are defective in systemic sclerosis. Arthritis Rheum 54: 2605-2615.

76. Kuwana M, Okazaki Y, Yasuoka H, Kawakami Y, Ikeda Y (2004) Defective vasculogenesis in systemic sclerosis. Lancet 364: 603-610.

77. Heiss C, Keymel S, Niesler U, Ziemann J, Kelm M, et al. (2005) Impaired progenitor cell activity in age-related endothelial dysfunction. J Am Coll Cardio 45: $1441-1448$.

78. Kondo T, Hayashi M, Takeshita K, Numaguchi Y, Kobayashi K, et al. (2004) Smoking cessation rapidly increases circulating progenitor cells in peripheral blood in chronic smokers. Arterioscler Thromb Vasc Biol 24: 1442-1447.

79. Michaud SE, Dussault S, Haddad P, Groleau J, Rivard A (2006) Circulating endothelial progenitor cells from healthy smokers exhibit impaired functional activities. Atherosclerosis 187: 423-432.

80. Botta R, Gao E, Stassi G, Bonci D, Pelosi E, et al. (2004) Heart infarct in NODSCID mice: therapeutic vasculogenesis by transplantation of human CD34+ cells and low dose CD34+KDR+ cells. FASEB J 18: 1392-1394.

81. Kawamoto A, Gwon HC, Iwaguro H, Yamaguchi Jl, Uchida S, et al. (2001) Therapeutic potential of ex vivo expanded endothelial progenitor cells for myocardial ischemia. Circulation 103: 634-637.

82. Madeddu P, Emanueli C, Pelosi E, Salis MB, Cerio AM, et al. (2004) Transplantation of low dose CD34+KDR+ cells promotes vascular and muscular regeneration in ischemic limbs. FASEB J 18: 1737-1739.

83. Rouhl RP, van Oostenbrugge RJ, Damoiseaux J, Tervaert JW, Lodder J (2008) Endothelial progenitor cell research in stroke: a potential shift in pathophysiological and therapeutical concepts. Stroke 39: 2158-2165.

84. Erbs S, Linke A, Adams V, Lenk K, Thiele H, et al. (2005) Transplantation of blood-derived progenitor cells after recanalization of chronic coronary artery occlusion: first randomized and placebo-controlled study. Circ Res 97: 756762

85. Li ZQ, Zhang M, Jing YZ, Zhang WW, Liu Y, et al. (2007) The clinical study of autologous peripheral blood stem cell transplantation by intracoronary infusion in patients with acute myocardial infarction (AMI). Int J Cardiol 115: 52-56.

86. Fernández-Avilés $F$, San Román JA, García-Frade J, Fernández ME, Peñarrubia MJ, et al. (2004) Experimental and clinical regenerative capability of human bone marrow cells after myocardial infarction. Circ Res 95: 742-748.

87. Meluzín J, Janousek S, Mayer J, Groch L, Hornácek I, et al. (2008) Three6-, and 12-month results of autologous transplantation of mononuclear bone marrow cells in patients with acute myocardial infarction. Int $\mathrm{J}$ Cardiol 128 185-192.

88. Meluzín J, Mayer J, Groch L, Janousek S, Hornácek I, et al. (2006) Autologous transplantation of mononuclear bone marrow cells in patients with acute myocardial infarction: the effect of the dose of transplanted cells on myocardial function. Am Heart J 152: 975.

89. Mocini D, Staibano M, Mele L, Giannantoni P, Menichella G, et al. (2006 Autologous bone marrow mononuclear cell transplantation in patients undergoing coronary artery bypass grafting. Am Heart J 151: 192-197.

90. Perin EC, Dohmann HF, Borojevic R, Silva SA, Sousa AL, et al. (2003) Transendocardial, autologous bone marrow cell transplantation for severe, chronic ischemic heart failure. Circulation 107: 2294-2302.

91. Perin EC, Dohmann HF, Borojevic R, Silva SA, Sousa AL, et al. (2004) Improved exercise capacity and ischemia 6 and 12 months after transendocardial injection of autologous bone marrow mononuclear cells for ischemic cardiomyopathy. Circulation 110: II213-218.

92. Strauer BE, Brehm M, Zeus T, Bartsch T, Schannwell C, et al. (2005) Regeneration of human infarcted heart muscle by intracoronary autologous bone marrow cell transplantation in chronic coronary artery disease: the IACT Study. J Am Coll Cardiol 46: 1651-1658.

93. Strauer BE, Brehm M, Zeus T, Köstering M, Hernandez A, et al. (2002) Repai of infarcted myocardium by autologous intracoronary mononuclear bone marrow cell transplantation in humans. Circulation 106: 1913-1918.

94. Numaguchi Y, Sone T, Okumura K, Ishii M, Morita Y, et al. (2006) The impact of the capability of circulating progenitor cell to differentiate on myocardial salvage in patients with primary acute myocardial infarction. Circulation 114: I114-119.

95. Döbert N, Britten M, Assmus B, Berner U, Menzel C, et al. (2004) Transplantation of progenitor cells after reperfused acute myocardial infarction: evaluation of perfusion and myocardial viability with FDG-PET and thallium SPECT. Eur J Nucl Med Mol Imaging 31: 1146-1151.

96. Lev El, Kleiman NS, Birnbaum Y, Harris D, Korbling M, et al. (2005) Circulating endothelial progenitor cells and coronary collaterals in patients with non-ST segment elevation myocardial infarction. J Vasc Res 42: 408-414.

97. Hristov M, Heussen N, Schober A, Weber C (2006) Intracoronary infusion of autologous bone marrow cells and left ventricular function after acute myocardial infarction: a meta-analysis. J Cell Mol Med 10: 727-733.

98. Dimmeler S, Zeiher AM, Schneider MD (2005) Unchain my heart: the scientific foundations of cardiac repair. J Clin Invest 115: 572-583.

99. Higashi Y, Kimura M, Hara K, Noma K, Jitsuiki D, et al. (2004) Autologous bone-marrow mononuclear cell implantation improves endothelium-dependent vasodilation in patients with limb ischemia. Circulation 109: 1215-1218.

100. Tateishi-Yuyama E, Matsubara H, Murohara T, Ikeda $U$, Shintani $S$ et al. (2002) Therapeutic angiogenesis for patients with limb ischaemia by autologous transplantation of bone-marrow cells: a pilot study and a randomised controlled trial. Lancet 360: 427-435.

101. Taguchi A, Matsuyama T, Moriwaki H, Hayashi T, Hayashida K, et al. (2004) Circulating CD34-positive cells provide an index of cerebrovascular function. Circulation 109: 2972-2975.

102. Ghani U, Shuaib A, Salam A, Nasir A, Shuaib U, et al. (2005) Endothelial progenitor cells during cerebrovascular disease. Stroke 36: 151-153. 